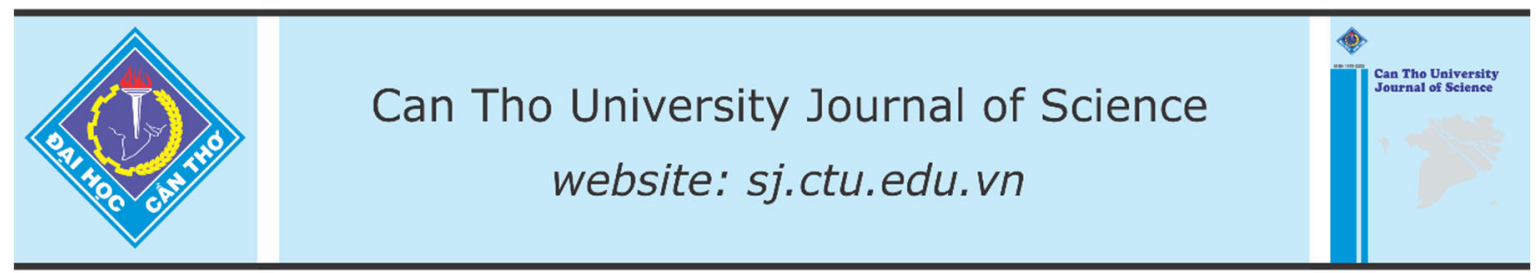

DOI: $10.22144 /$ ctu.jen.2019.010

\title{
Variation in morphometric characteristics between cultured and wild striped snakehead (Channa striata) populations in the Mekong Delta
}

\author{
Duong Thuy Yen ${ }^{1 *}$, Vo Ngoc Duyen ${ }^{2}$, Tran Thi Thanh Hien ${ }^{1}$, Robert Pomeroy ${ }^{3}$ and Egna Hillary ${ }^{4}$ \\ ${ }^{I}$ College of Aquaculture and Fisheries, Can Tho University, Vietnam \\ ${ }^{2}$ Aquaculture Master Student - Course 23, Can Tho University, Vietnam \\ ${ }^{3}$ University of Connecticut, Department of Agricultural and Resource Economics, Groton, Connecticut, USA \\ ${ }^{4}$ AquaFish Innovation Lab, Oregon State University, USA \\ *Correspondence: Duong Thuy Yen (email: thuyyen@ctu.edu.vn)
}

\section{Article info.}

Received 03 Aug 2018

Revised 26 Oct 2018

Accepted 29 Mar 2019

\section{Keywords}

Channa striata, cultured fish, morphological plasticity, snakehead, wild population

\section{ABSTRACT}

Fish in captive conditions can change their morphology differently from their origin in the wild. Thus, morphological characteristics are commonly used for population identification. In this study, morphometric differences among six cultured and wild populations of striped snakehead (Channa striata) in the Mekong Delta were evaluated. Cultured fish were collected from three hatcheries in Hau Giang, An Giang, and Dong Thap provinces, where snakehead farming is commonly practiced. Wild fish were sampled nearby three conservation areas in Long An, Ca Mau, and Hau Giang provinces. Twenty-two morphometric measurements were converted into ratios to standard length or head length (indices) or adjusted for body size effects by using Elliot et al.'s (1995) approach. Univariate analyses showed that morphometric characteristics of snakehead were significantly different among six populations $(P<0.01)$. In fact, wild snakehead fish exhibited higher morphological diversity within and among populations compared with the cultured ones. Principal component analyses based on two treated data types consistently indicated that head size and caudal peduncle height were important traits to distinguish wild and cultured populations, regardless of sampling localities. Wild snakehead had longer but smaller head and narrower caudal peduncle than the cultured ones. The morphometric indices-based approach resulted in higher proportions of correct individual assignment (90.7\%) than that based on body size-adjusted measurements (79.6\%), partly due to body size effects.

Cited as: Yen, D.T., Duyen, V.N., Hien, T.T.T., Pomeroy, R. and Hillary, E., 2019. Variation in morphometric characteristics between cultured and wild striped snakehead (Channa striata) populations in the Mekong Delta. Can Tho University Journal of Science. 11(1): 70-77.

\section{INTRODUCTION}

Morphological analysis, together with other advanced methods, is considered a simple and common tool for fish stock identification, especially for differentiating between hatchery and wild fish sources (Cadrin, 2000; Dwivedi and Dubey, 2013; Anumudu and Mojekwu, 2015). Due to combination effects of genetics, evironment factors, and development stages, fish morphological characteristics, mainly morphometric traits can vary among populations (Wimberger, 1992; Cadrin, 
2000). Population differentiation is important for both aquaculture and fisheries. In aquaculture, selected broodstock individuals should be known origin because of strain variation in different traits involving production (Dunham et al., 2014). In fisheries managements, correct individual assignments are useful to manage hatchery escapees (Šegvić-Bubić et al., 2014). Morphological analysis has been applied to classify wild and cultured populations in many marine fish species, e.g. sea bream (Grigorakis et al., 2002); Atlantic cod (Wringe et al., 2015) but information for freshwater fish is still limited.

Striped snakehead species has been cultured for more than two decades in freshwater areas in the Mekong Delta (Sinh et al., 2014). Since domestication, the species has experienced a large change in food types and feeding behavior of a carnivore from the wild to culture conditions. In culture ponds, snakehead were fed dead trash fish and/or commercial pellets. The species also exposes to living space change, from open habitat in the wild to limited space in ponds, which in turn affects their locomotion. Such changes can result in morphological variation, especially head characteristics (Turan et al., 2005; Ward-Campbell and Beamish, 2005; Janhunen et al., 2009). Morphological responses can be different among species, among populations or even among individuals within a population (Cadrin, 2000), resulting in morphological plasticity. A previous study on snakehead morphology and genetics found that two snakehead morphotypes observed in aquaculture, including "triangle-head" snakehead and "square-head" snakehead, differed in the shape of their head but they had identical sequences of Cytochrome $\mathrm{C}$ oxidase submit I, a mitochondrial gene, compared to wild striped snakehead Channa striata (Nguyen and Duong, 2016). However, sampling each morphotype with similar body sizes in one location in that study might limit in estimating levels of inter-population variation of striped snakehead.

The objectives of the present study were to quantify levels of variation in morphometric characteristics between wild and cultured striped snakehead populations in the Mekong Delta, and identify important traits contributing to population differentiation. The results could be applied in practice of individuals assignments for this species.

\section{MATERIALS AND METHODS}

\subsection{Fish sampling}

Striped snakehead were sampled from three cultured and three wild populations. Cultured populations were selected from hatcheries in three provinces where snakehead farming is commonly practiced, including Hau Giang, An Giang, and Dong Thap provinces. According to hatchery managers, the fish in these farms have been domesticated for $4-6$ generations and locally they are called "ca loc dau nhim" (triangle-head snakehead). A previous study showed that triangle-head snakehead is one of phenotypes found in aquaculture conditions of striped snakehead Channa striata (Nguyen and Duong, 2016). Meanwhile, wild fish were sampled from conservation areas to minimize possibilities of misidentification between wild and escaped cultured fish. Three distant areas were selected for sampling, including Lang Sen Wetland Reserve (Long An), U Minh Ha melaleuca forest (Ca Mau), and Lung Ngoc Hoang Wetland (Hau Giang).

A total of 279 samples from 6 populations (34-66 samples/population) were collected (Table 1). Samples were kept alive or in ice and then transported immediately to the laboratory for morphological analyses.

\subsection{Morphometric measurements}

Morphometric parameters were measured based on the guidance of Rainboth (1996) and Tran et al. (2013). Each individual fish was weighed and taken measurements (using calipers, accuracy $0.1 \mathrm{~mm}$ ) of body lengths, fin lengths, distance from the mouth to fins (or distance before fins), caudal fin length and height, and head morphometrics. In addition to common measurements of many fish species, head width of snakehead was measured at two positions to evaluate the shape of the head including small head width (SHW) measured right after the mouth, and large head width (LHW) measured at the largest position of the head (Nguyen and Duong, 2016).

\subsection{Data analysis}

Raw data were treated in two ways (ratios and adjusted measurements) before further statistical tests. First, measurements were calculated ratios to either standard length or head length (hereby called morphometric indices). Twelve parameters indicating body shape (Table 2) and fin lengths (Table 3) were converted to the percentage of standard length. Eight head measurements were calculated ratios to head length (Table 4).

Given that most of morphometric indices linearly correlate with body length, and there was statistical variation in fish sizes among populations (Table 1). Data were adjusted based on the approach given by Elliott et al. (1995) as follows:

$\mathrm{M}_{\mathrm{adj}}=\mathrm{M}_{0}\left(\mathrm{~L}_{\mathrm{s}} / \mathrm{L}_{0}\right)^{\mathrm{b}}$ 
Where $\mathrm{M}_{\mathrm{adj}}$ is an adjusted measurement; $\mathrm{M}_{0}$ is the original measured character; $\mathrm{L}_{\mathrm{s}}$ mean standard length of all individuals used in the study (regardless their origin population); $\mathrm{L}_{0}$ is the standard length of each individual; $\mathbf{b}$ is the slope of the regression $\log \mathrm{M}_{0}$ on $\log \mathrm{L}_{0}$ using all individuals. Value $\mathbf{b}$ was estimated for each character.

Adjusted measurements were tested if they were correlated with the standard length. No such correlations were detected, indicating that the effects of body sizes on morphometric characters were removed.

Morphometric indices and adjusted measurements were subsequently used to test for statistical differences between wild and cultured groups and among populations (or locations) using univariate analyses and DUNCAN multiple range tests. In addition, principal component analysis (PCA) was applied to identify important characters that contribute to differences among populations and estimate variation explained by main principal component (PC) (Cadrin, 2000). Two types of data (morphometric indices and adjusted measurements) were then submitted to discriminant analysis (DA) in order to visualize the population differentiation and evaluate the cross-validated correction of individual assignment to their origin populations. Statistical analyses were performed using SPSS 22.0.

\section{RESULTS}

\subsection{Fish sizes}

Fish sizes were significantly different among populations $(\mathrm{P}<0.01)$. Their weight and total length ranged from 70 to $392 \mathrm{~g}$ and $18.4-34.6 \mathrm{~cm}$, respectively (Table 1). Differences in fish sizes could affect the morphometric indices. Therefore, morphometric comparisons among populations were evaluated using both ratios and adjusted data.

Table 1: Sample sizes of wild (W) and cultured (C) snakehead populations used in the study

\begin{tabular}{lrrrrr}
\hline Populations & N & \multicolumn{2}{c}{ Weight (g) } & \multicolumn{2}{c}{ Length (cm) } \\
\hline & & Min-Max & Mean \pm SD & Min-Max & Mean \pm SD \\
W. Long An (LA) & 34 & $67.6-392.9$ & $154.9 \pm 66.8^{\mathrm{b}}$ & $18.7-37.0$ & $25.2 \pm 3.7^{\mathrm{c}}$ \\
W. Ca Mau (CM) & 34 & $80.3-295.5$ & $146.1 \pm 60.2^{\mathrm{b}}$ & $22.1-34.6$ & $26.7 \pm 3.2^{\mathrm{d}}$ \\
W. Hau Giang (HG) & 46 & $69.3-132.1$ & $91.2 \pm 13.8^{\mathrm{a}}$ & $18.7-25.2$ & $21.6 \pm 1.5^{\mathrm{b}}$ \\
C. Hau Giang (HG) & 50 & $233.0-372.6$ & $299.5 \pm 33.8^{\mathrm{d}}$ & $27.6-33.6$ & $31.1 \pm 1.5^{\mathrm{e}}$ \\
C. An Giang (AG) & 66 & $99.3-311.0$ & $175.9 \pm 45.2^{\mathrm{c}}$ & $22.0-31.3$ & $26.1 \pm 2.2^{\text {cd }}$ \\
C. Dong Thap (DT) & 49 & $70.4-119.8$ & $87.1 \pm 11.0^{\mathrm{a}}$ & $18.4-23.5$ & $20.6 \pm 1.1^{\mathrm{a}}$ \\
\hline
\end{tabular}

Values in the same column with the same letter(s) are not significantly different $(P>0.05)$

\subsection{Morphometric variation among populations}

Univariate analyses showed that all (22) morphometric indices (Table 2, 3 and 4) significantly differed among populations $(\mathrm{P}<0.01)$. However, when fish populations were pooled into wild and cultured groups, no differences were found in 9 indices, such as body depth (BD), distances before fins, eye diameter (ED), and mouth characters. The discrepancy between two ways of comparison was due to high variations in these traits within each group. The head shape varied between two groups. Wild fish had longer (HL/LS: $31.7 \pm 2.8 \%$ ) but smaller (SHW/HL: $29.3 \pm 3.2 \%$ and LHW/HL: $55.4 \pm 4.5 \%$ ) head compared to cultured fish (HL/LS: $30.5 \pm 1.5 \%$, SHW/HL: $30.4 \pm 2.7 \%$ and LHW/HL: $58.8 \pm 3.0$ ). In addition, wild fish had narrower caudal peduncle height $(\mathrm{HCP} / \mathrm{Ls}$ : $8.6 \pm 1.4 \%)$ than that of cultured fish $(9.0 \pm 1.1 \%)$. The lengths of four fins also statistically differed between two groups $(\mathrm{P}<0.05)$, but the magnitude of differences was small (Table 3 ).

Results based on adjusted measurements showed similar trends to those of morphometric indices (data not shown). Body depth and distance before fins were highly significantly different among six populations $(\mathrm{P}<0.01)$, but these indices became insignificant when comparing two groups of wild and cultured fish $(\mathrm{P}>0.05)$. 
Table 2: Morphometric indices $(\% \pm$ SD) of body parameters compared to standard length of wild (W) and cultured $(C)$ snakehead populations

\begin{tabular}{lrrrrrrrr}
\hline Populations & BD/Ls & HL/Ls & dfD/Ls & dfP/Ls & dfV/Ls & dfA/Ls & LCP/Ls & HCP/Ls \\
\hline Wild & $15.3 \pm 1.7^{\mathrm{A}}$ & $31.7 \pm 2.8^{\mathrm{B}}$ & $36.2 \pm 3.1^{\mathrm{A}}$ & $33.5 \pm 2.9^{\mathrm{B}}$ & $35.4 \pm 2.8^{\mathrm{A}}$ & $56.1 \pm 3.9^{\mathrm{A}}$ & $8.6 \pm 1.4^{\mathrm{A}}$ & $8.6 \pm 1.4^{\mathrm{A}}$ \\
Cultured & $15.1 \pm 1.2^{\mathrm{A}}$ & $30.5 \pm 1.5^{\mathrm{A}}$ & $36.0 \pm 1.9^{\mathrm{A}}$ & $32.9 \pm 1.7^{\mathrm{A}}$ & $35.0 \pm 1.5^{\mathrm{A}}$ & $56.1 \pm 2.1^{\mathrm{A}}$ & $8.5 \pm 1.1^{\mathrm{A}}$ & $9.0 \pm 1.1^{\mathrm{B}}$ \\
\hline Comparing & separate six populations & & & & & & \\
\hline W. LA & $16.1 \pm 1.8^{\mathrm{c}}$ & $33.8 \pm 1.5^{\mathrm{c}}$ & $38.1 \pm 1.4^{\mathrm{c}}$ & $35.3 \pm 1.2^{\mathrm{c}}$ & $36.8 \pm 1.3^{\mathrm{c}}$ & $56.9 \pm 1.1^{\mathrm{bc}}$ & $8.9 \pm 1.5^{\mathrm{c}}$ & $8.9 \pm 0.7^{\mathrm{bc}}$ \\
W. CM & $13.9 \pm 2.9^{\mathrm{a}}$ & $30.7 \pm 5.5^{\mathrm{a}}$ & $34.1 \pm 5.7^{\mathrm{a}}$ & $31.7 \pm 5.6^{\mathrm{a}}$ & $33.7 \pm 5.8^{\mathrm{a}}$ & $54.7 \pm 8.6^{\mathrm{a}}$ & $7.2 \pm 1.4^{\mathrm{a}}$ & $8.2 \pm 1.4^{\mathrm{a}}$ \\
W. HG & $15.1 \pm 1.2^{\mathrm{b}}$ & $32.7 \pm 1.1^{\mathrm{b}}$ & $36.4 \pm 1.7^{\mathrm{b}}$ & $33.9 \pm 1.4^{\mathrm{b}}$ & $35.6 \pm 1.5^{\mathrm{b}}$ & $56.0 \pm 1.8^{\mathrm{bc}}$ & $9.1 \pm 1.3^{\mathrm{c}}$ & $8.2 \pm 0.5^{\mathrm{a}}$ \\
C. HG & $16.0 \pm 0.9^{\mathrm{c}}$ & $29.7 \pm 1.0^{\mathrm{a}}$ & $34.6 \pm 1.2^{\mathrm{a}}$ & $32.3 \pm 1.1^{\mathrm{a}}$ & $34.2 \pm 0.9^{\mathrm{a}}$ & $55.2 \pm 1.5^{\mathrm{ab}}$ & $7.8 \pm 0.7^{\mathrm{b}}$ & $8.9 \pm 0.5^{\mathrm{bc}}$ \\
C. AG & $14.3 \pm 1.1^{\mathrm{a}}$ & $29.9 \pm 1.0^{\mathrm{a}}$ & $35.8 \pm 1.2^{\mathrm{b}}$ & $32.2 \pm 1.1^{\mathrm{a}}$ & $34.5 \pm 1.1^{\mathrm{a}}$ & $55.5 \pm 1.4^{\mathrm{ab}}$ & $8.1 \pm 0.6^{\mathrm{b}}$ & $9.2 \pm 0.5^{\mathrm{c}}$ \\
C. DT & $15.3 \pm 0.9^{\mathrm{b}}$ & $32.0 \pm 1.4^{\mathrm{b}}$ & $37.7 \pm 1.9^{\mathrm{c}}$ & $34.5 \pm 1.7^{\mathrm{b}}$ & $36.5 \pm 1.3^{\mathrm{bc}}$ & $57.8 \pm 2.4^{\mathrm{c}}$ & $9.6 \pm 0.9^{\mathrm{a}}$ & $8.7 \pm 0.8^{\mathrm{b}}$ \\
\hline
\end{tabular}

Note: $B D$; body depth; Ls - standard length; df distance from the mount tip to fins of dorsal (dfD), pelvic (dfP), ventral $(d f V)$, and anal (dfA); LCP - Length of caudal peduncle; HCP - Height of caudal peduncle. Values in the same column with the same (capitalized or lowercase) letter(s) are not significantly different $(P>0.05)$.

Table 3: Ratios (\%) of fin lengths to standard length of wild (W) and cultured (C) snakehead populations

\begin{tabular}{lcccr}
\hline Populations & DFL/Ls & PFL/Ls & VFL/Ls & AFL/Ls \\
\hline Wild & $61.4 \pm 4.7^{\mathrm{A}}$ & $17.9 \pm 1.6^{\mathrm{B}}$ & $13.0 \pm 1.1^{\mathrm{B}}$ & $38.0 \pm 2.9^{\mathrm{A}}$ \\
Cultured & $61.7 \pm 2.0^{\mathrm{B}}$ & $17.4 \pm 1.0^{\mathrm{A}}$ & $12.6 \pm 0.8^{\mathrm{A}}$ & $38.4 \pm 1.7^{\mathrm{B}}$ \\
\hline \multicolumn{2}{l}{ Comparing separate six populations } & & & \\
\hline W. LA & $60.5 \pm 1.8^{\mathrm{ab}}$ & $18.8 \pm 1.2^{\mathrm{c}}$ & $13.4 \pm 0.7^{\mathrm{c}}$ & $38.1 \pm 2.1^{\mathrm{b}}$ \\
W. CM & $62.8 \pm 9.1^{\mathrm{c}}$ & $18.4 \pm 3.0^{\mathrm{bc}}$ & $12.7 \pm 2.1^{\mathrm{b}}$ & $38.6 \pm 5.7^{\mathrm{b}}$ \\
W. HG & $59.1 \pm 1.8^{\mathrm{a}}$ & $17.9 \pm 1.2^{\mathrm{ab}}$ & $12.9 \pm 0.8^{\mathrm{b}}$ & $36.7 \pm 1.9^{\mathrm{a}}$ \\
C. HG & $62.8 \pm 1.8^{\mathrm{c}}$ & $17.5 \pm 1.0^{\mathrm{a}}$ & $12.3 \pm 0.5^{\mathrm{a}}$ & $38.6 \pm 1.8^{\mathrm{b}}$ \\
C. AG & $60.8 \pm 1.4^{\mathrm{ab}}$ & $17.3 \pm 0.8^{\mathrm{a}}$ & $12.3 \pm 0.6^{\mathrm{a}}$ & $38.3 \pm 1.4^{\mathrm{b}}$ \\
C. DT & $61.6 \pm 2.4^{\mathrm{bc}}$ & $17.3 \pm 1.2^{\mathrm{a}}$ & $13.5 \pm 0.6^{\mathrm{c}}$ & $38.3 \pm 1.9^{\mathrm{b}}$ \\
\hline
\end{tabular}

Note: DFL - Dorsal fin length; PFL - pectoral fin length; VFL - Ventral fin length; AFL - Anal fin length. Values in the same column with the same (capitalized or lowercase) letter(s) are not significantly different $(P>0.05)$

Table 4: Morphometric indices $(\% \pm$ SD) of head characters compared to head length of wild $(W)$ and cultured $(C)$ snakehead populations

\begin{tabular}{|c|c|c|c|c|c|c|c|}
\hline Populations & HD/HL & SHW/HL & LHW/HL & SHW/LHW & ED/HL & IW/HL & MW/HL \\
\hline Wild & $45.4 \pm 3.0^{\mathrm{A}}$ & $29.3 \pm 3.2^{\mathrm{A}}$ & $55.4 \pm 4.5^{\mathrm{A}}$ & $53.0 \pm 5.1^{\mathrm{B}}$ & $13.6 \pm 1.3^{\mathrm{A}}$ & $24.7 \pm 1.8^{\mathrm{A}}$ & $36.5 \pm 3.6^{\mathrm{A}}$ \\
\hline Cultured & $46.9 \pm 2.5^{\mathrm{B}}$ & $30.4 \pm 2.7^{\mathrm{B}}$ & $58.8 \pm 3.0^{\mathrm{B}}$ & $51.8 \pm 4.9^{\mathrm{A}}$ & $13.8 \pm 1.3^{\mathrm{A}}$ & $25.9 \pm 1.3^{\mathrm{B}}$ & $36.4 \pm 2.5^{\mathrm{A}}$ \\
\hline \multicolumn{8}{|c|}{ Comparing separate six populations } \\
\hline W. LA & $44.0 \pm 2.7^{\mathrm{a}}$ & $28.3 \pm 1.9^{\mathrm{bc}}$ & $54.0 \pm 2.7^{\mathrm{b}}$ & $52.6 \pm 4.5^{\mathrm{bc}}$ & $13.3 \pm 1.1^{\mathrm{b}}$ & $23.9 \pm 1.2^{b}$ & $39.6 \pm 4.5^{\mathrm{d}}$ \\
\hline W. CM & $43.8 \pm 2.2^{\mathrm{a}}$ & $27.7 \pm 3.2^{\mathrm{ab}}$ & $54.7 \pm 2.7^{\mathrm{b}}$ & $50.8 \pm 6.2^{\mathrm{ab}}$ & $14.0 \pm 1.2^{\mathrm{cd}}$ & $24.4 \pm 1.4^{\text {ba }}$ & $36.2 \pm 3.3^{\mathrm{bc}}$ \\
\hline W. HG & $44.0 \pm 2.1^{\mathrm{a}}$ & $27.1 \pm 1.8^{\mathrm{a}}$ & $50.1 \pm 2.9^{\mathrm{a}}$ & $54.1 \pm 3.2^{\mathrm{c}}$ & $13.8 \pm 1.1^{\mathrm{c}}$ & $23.0 \pm 0.8^{\mathrm{a}}$ & $31.6 \pm 3.3^{\mathrm{a}}$ \\
\hline C. $\mathrm{HG}$ & $48.5 \pm 2.3^{\mathrm{d}}$ & $32.1 \pm 3.8^{\mathrm{e}}$ & $60.1 \pm 2.9^{d}$ & $53.5 \pm 7.1^{\mathrm{c}}$ & $12.6 \pm 1.1^{\mathrm{a}}$ & $26.7 \pm 1.5^{\mathrm{e}}$ & $37.4 \pm 3.1^{\mathrm{c}}$ \\
\hline C. $\mathrm{AG}$ & $46.6 \pm 2.2^{\mathrm{c}}$ & $29.2 \pm 1.4^{\mathrm{c}}$ & $59.2 \pm 2.3^{\mathrm{d}}$ & $49.4 \pm 2.5^{\mathrm{a}}$ & $14.2 \pm 1.0^{\mathrm{cd}}$ & $26.0 \pm 1.2^{\mathrm{d}}$ & $36.4 \pm 2.0^{\mathrm{bc}}$ \\
\hline C. DT & $45.6 \pm 2.5^{\mathrm{b}}$ & $30.3 \pm 1.8^{\mathrm{d}}$ & $56.8 \pm 3.2^{\mathrm{c}}$ & $53.4 \pm 2.7^{\mathrm{c}}$ & $14.4 \pm 0.9^{\mathrm{d}}$ & $25.1 \pm 1.2^{\mathrm{c}}$ & $35.5 \pm 2.2^{\mathrm{b}}$ \\
\hline
\end{tabular}

Note: HL - Head length; HD - Head depth; SHW - Small head width; LHW - Large head width; ED - eye diameter; IW - Inter-orbital width; MW-Mouth width. Ratios of upper jaw and lower jaw to head length (similar between wild and cultured populations $41 \%$ and $42 \%$, respectively) and were not included in this table. Values in the same column with the same (capitalized or lowercase) letter(s) are not significantly different $(P>0.05)$.

\subsection{PCA and DA for population differentiation}

PCA based on morphometric indices (Fig. 1A) showed that wild Ca Mau and cultured Dong Thap populations were relatively separated from the others. Meanwhile, wild Long An and wild Hau Giang were compounded, similar to two cultured populations of Hau Giang and An Giang. The first principal component (PC1) explained $33.9 \%$ variation, mainly variation among individuals of six populations. Main morphometric indices importantly contributing to PC1 included distance before fins (i.e. dfD, dfV, dfP, and dfA), head length, body depth, fin lengths, caudal peduncle length and height. The PC2 explained other $15.3 \%$ of variation, mainly between two groups of cultured and wild fish. They 
were differentiated by head morphometric indices in Table 4, especially head width (SHW, LHW) and head depth.

When effects of body sizes were taken into account, PCA based on adjusted measurements (Fig. 1B) showed a slightly different pattern compared to morphometric indices. Three cultured populations became more compounded together, while three wild populations were more divergent within and among populations. All adjusted body and head

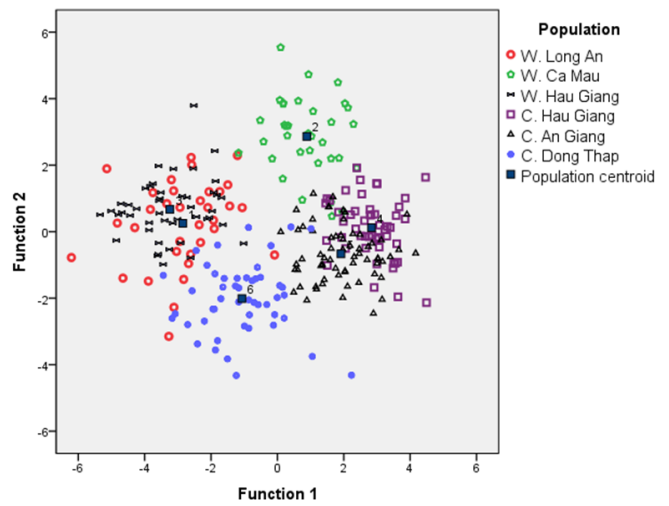

(A) characters contributed to $\mathrm{PC} 1$, resulting in the increase of variation explained up to $62.5 \%$. PC2 explained other $12.7 \%$ of variation with the contribution of mouth characters, lengths of dorsal fin and anal fins.

Although morphometric indices and adjusted data provide some different outputs, both data revealed a similar separation between wild and cultured fish groups.

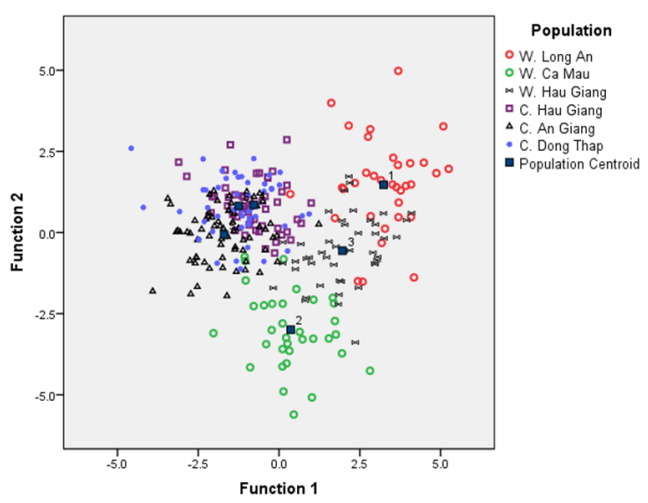

(B)

Fig. 1: Canonical discriminant analysis based on morphometric indices (A) and adjusted measurements (B)

Results of correct individual classification based on morphometric indices (Table 5) of cultured fish (93.9-94.0\%) overall were higher than that of wild fish $(70.6-94.1 \%)$. Individual classification using adjusted measurements (Table 6) showed opposite results where lower corrections were observed in cultured fish $(68-83.6 \%)$ than in wild fish $(79.4-$ $85.3 \%)$. The overall correct individual assignment (across six populations) into their original groups was $90.7 \%$ for morphometric indices and $79.6 \%$ for adjusted measurements. Misclassifications occurred mainly within each group (either wild or cultured). Based on morphometric indices, incorrect assignments of wild fish into cultured fish varied from 2.9 to $5.9 \%$, and vice versa $4.1 \%$ (only observed in cultured Dong Thap population).

Table 5: The percentage of individual classification into six snakehead populations based on morphometric indices

\begin{tabular}{lrrrrrrr}
\hline Populations & $\mathbf{1}$ & $\mathbf{2}$ & $\mathbf{3}$ & $\mathbf{4}$ & $\mathbf{5}$ & $\mathbf{6}$ & Total (N) \\
\hline 1. W. Long An & $\mathbf{7 0 . 6}$ & 0.0 & 23.5 & 0 & 2.9 & 2.9 & $100(34)$ \\
2. W. Ca Mau & 0 & $\mathbf{9 4 . 1}$ & 0 & 0 & 5.9 & 0 & $100(34)$ \\
3. W. Hau Giang & 6.5 & 0.0 & $\mathbf{9 1 . 3}$ & 0 & 0.0 & 2.2 & $100(46)$ \\
4. C. Hau Giang & 0 & 0 & 0 & $\mathbf{9 4 . 0}$ & 6.0 & 0 & $100(50)$ \\
5. C. An Giang & 0 & 0 & 0 & 6.1 & $\mathbf{9 3 . 9}$ & 0 & $100(66)$ \\
6. C. Dong Thap & 0 & 0 & 4.1 & 0 & 2.0 & $\mathbf{9 3 . 9}$ & $100(49)$ \\
\hline
\end{tabular}

Table 6: The percentage of individual classification into six snakehead populations based on adjusted measurements

\begin{tabular}{lrrrrrrr}
\hline Populations & $\mathbf{1}$ & $\mathbf{2}$ & $\mathbf{3}$ & $\mathbf{4}$ & $\mathbf{5}$ & $\mathbf{6}$ & Total (N) \\
\hline 1. W. Long An & $\mathbf{7 9 . 4}$ & 0.0 & 17.6 & 2.9 & 0.0 & 0.0 & 100.0 \\
2. W. Ca Mau & 0.0 & $\mathbf{8 5 . 3}$ & 5.9 & 0.0 & 5.9 & 2.9 & 100.0 \\
3. W. Hau Giang & 6.5 & 4.3 & $\mathbf{8 4 . 8}$ & 0.0 & 4.3 & 0.0 & 100.0 \\
4. C. Hau Giang & 0.0 & 0.0 & 2.0 & $\mathbf{6 8 . 0}$ & 14.0 & 16.0 & 100.0 \\
5. C. An Giang & 0.0 & 0.0 & 1.5 & 4.5 & $\mathbf{8 3 . 6}$ & 10.4 & 100.0 \\
6. C. Dong Thap & 0.0 & 0.0 & 2.1 & 10.4 & 10.4 & $\mathbf{7 7 . 1}$ & 100.0 \\
\hline
\end{tabular}




\section{DISCUSSION}

Important results of the study reveal high levels of inter-population variation in morphometric characteristics of snakehead (i.e. all morphometric traits were highly significantly different among populations), resulting in high possibilities of correct individual assignments into their original populations. Low (maximum $8.9 \%$ ) of mis-classifications between wild and cultured fish implies that morphometric traits can be used for population-origin identification of snakehead. A previous study on the same species also reported high variations among wild populations in four geographic distance areas in Malaysia (Song et al., 2013). In other species, morphology-based distinguishing between wild and cultured fish had higher rates of mis-classification compared to the present work. For example, misclassification was $20 \%$ in kissing gourami Helostoma temminkii (Nguyen Phuong Thao and Duong Thuy Yen, 2017) or 18.2\% in sea bream Sparus aurata (Šegvić-Bubić et al., 2014)). However, in bighead catfish Clairas macrocephalus in the Mekong Delta, Duong et al. (2017) reported that only $1.0 \%$ and $2.5 \%$ wild and cultured individuals, respectively, were misclassified. Accuracy levels of PCA-based individual assignments vary among studies (or species) could be due to different magnitudes of morphometric divergence among (compared to within) investigated groups.

Both types of data (morphometric indices and adjusted measurements) indicate that traits differentiating among snakehead populations include (listed in a descent order of importance) distance before fins, head size (length, width and depth), BD and the height of caudal peduncle (HCP). Among which, $\mathrm{BD}$ and distance before fins were highly significantly different among six populations, but these indices became insignificant when three populations within each group were pooled into wild and cultured groups. These statistical results can be explained by high variation in these traits within each group, indicating these traits were influenced by locality, mainly due to environment. Characters that are consistent between two ways of comparisons in contributing to population differences are important traits for stock identification (Cadrin, 2000). These traits of snakehead are head morphometrics (i.e. head length, width and depth) and HCP. Head morphometrics and HCP are also important traits to distinguish wild and cultured populations in other fish species, such as bighead catfish (Duong et al., 2017), African catfish Clarias gariepinus (Turan et al., 2005), climbing perch Anabas testudineus (Duong Thuy Yen and Truong Ngoc Trinh, 2013), Lake Trout Salvelinus namaycush (Muir et al.,
2014), Arctic charr Salvelinus alpinus (Janhunen et al., 2009), etc. However, different species vary differently in their head between two living environments. For snakehead, when standard lengths are equal, wild fish have longer but smaller head and narrower caudal peduncle compared to cultured individuals. Shine (1989) proposed that variation in head morphology among individuals was affected by flexible adaptation to environmental conditions, especially diets and competition. Larger head could be advantageous for fish in more competitive conditions (Shine, 1989). Snakehead species is aggressive feeding; therefore, cultured snakehead individuals expose to higher levels of competition for food, resulting in larger head size compared to wild snakehead. Similar observation was also reported for climbing perch (Duong Thuy Yen and Truong Ngoc Trinh, 2013). Meanwhile, wild snakehead with longer and smaller head and smaller HCP can benefit for faster movements.

The study also found that wild snakehead showed higher morphological diversity within and among populations compared to cultured ones. This finding can be interpreted from the compounded grouping of three cultured snakehead populations (C. Hau Giang, C. An Giang, and C. Dong Thap) and the scatter distribution of three wild populations (W. Long An, W. Ca Mau, and W. Hau Giang) shown in the discriminant analysis diagram in Fig. 1B. Environment plays an important role in morphological variation in fish (Langerhans et al., 2003; Anumudu and Mojekwu, 2015; Wringe et al., 2015). Environmental fluctuation and open habitat in the wild can lead to more plasticity in morphology of wild snakehead fish compared to culture fish living in more stable and limited living space in captive conditions. Among wild populations, the diverse environments of wetland reserve in Long An and melaleuca forest in $\mathrm{Ca} \mathrm{Mau}$ can also explain a large difference in morphometrics between two wild (Long An and Ca Mau) populations (as shown by the separation apart of two populations in the DA diagram, Fig. 1B). In addition, more flexible of wild fish's behavior (in response to environment conditions) also results in high morphological plasticity (Wimberger, 1992). The morphological plasticity, in turn, allows wild fish to evolve and better adapt to extraordinary environment (Lande, 2009).

The present study on snakehead provides an additional empirical example of fish size-control when investigating inter-population variation in morphology. Morphometric indices are commonly used; however, body size effects on morphometric indices may not be completely removed (Elliott et al., 1995; Cadrin, 2000; Anumudu and Mojekwu, 2015). In 
agreement with previous studies, most morphometric indices of snakehead were still linearly correlated with standard length (data not shown). In addition, population differentiation of three cultured populations based on morphometric indices was more separated (Fig. 1A) and with higher proportion of correct individual assignment (Table 5) than those based on adjusted measurements (Fig. 1B and Table 6), due to partly effects of body sizes. Therefore, a body size-control approach has been recommended to be applied for studying intraspecific morphological diversity of fish species (Cadrin, 2000; Valentin et al., 2008; Anumudu and Mojekwu, 2015).

\section{CONCLUSIONS}

Morphometric characteristics of snakehead are highly variable among populations. Wild snakehead fish have higher morphological diversity within and among populations compared to cultured ones.

Important morphometric characteristics that contributed to differentiating among snakehead populations include distance before fins, head size (length, width and depth), BD and the HCP. In which, head size and HCP are more important traits to distinguish wild and cultured populations, regardless sampling localities.

\section{ACKNOWLEDGMENTS}

This research is a component of the Feed the Future Innovation Lab for Collaborative Research on Aquaculture and Fisheries, made possible by the generous support of the American people through the United States Agency for International Development (USAID), Grant No. EPP-A-00-06-00012-00; and by contributions from participating institutions. The contents are the responsibility of the authors and do not necessarily reflect the views or endorsement of USAID, the United States Government, or the AquaFish Innovation Lab.

\section{REFERENCES}

Anumudu, C., and Mojekwu, T., 2015. Advanced techniques for morphometric analysis in fish. Journal of Aquaculture Research and Development, 6(8): 6-11.

Cadrin, S.X., 2000. Advances in morphometric identification of fishery stocks. Reviews in Fish Biology and Fisheries, 10(1): 91-112.

Dunham, R.A., Ramboux, A.C.R., and Perera, D.A., 2014. Effect of strain on the growth, survival and sexual dimorphism of channel $\mathrm{x}$ blue catfish hybrids grown in earthen ponds. Aquaculture, 420-421: S20-S24.

Duong, T.Y., Nguyen, T.T. and Pham, T.L., 2017. Morphological differentiation among cultured and wild Clarias macrocephalus, C. macrocephalus x C. gariepinus hybrids, and their parental species in the Mekong delta, Viet Nam. International Journal of Fisheries and Aquatic Studies, 5(1): 233-240.

Duong Thuy Yen and Truong Ngoc Trinh, 2013. Morphological comparison between new phenotype and wild strains of climbing perch (Anabas testudineus). Can Tho University Journal of Science, 29: 86-95 (in Vietnamese).

Dwivedi, A.K., and Dubey, V.K., 2013. Advancements in morphometric differentiation: A review on stock identification among fish populations. Reviews in Fish Biology and Fisheries, 23(1): 23-39.

Elliott, N.G., Haskard, K. and Koslow, J.A., 1995. Morphometric analysis of orange roughy (Hoplostethus atalanticus) off the continental slope of southern Australia. Journal of Fish Biology, 46(2): 202-220.

Grigorakis, K., Alexis, M.N., Anthony Taylor, K.D. and Hole, M., 2002. Comparison of wild and cultured gilthead sea bream (Sparus aurata); composition, appearance and seasonal variations. International Journal of Food Science and Technology, 37(5): 477-484.

Janhunen, M., Peuhkuri, N. and Piironen, J., 2009. Morphological variability among three geographically distinct Arctic charr (Salvelinus alpinus L.) populations reared in a common hatchery environment. Ecology of Freshwater Fish, 18(1): 106-116.

Lande, R., 2009. Adaptation to an extraordinary environment by evolution of phenotypic plasticity and genetic assimilation. Journal of Evolutionary Biology, 22(7): 1435-1446.

Langerhans, R.B., Layman, C.A., Langerhans, A. K., and Dewit, T.J., 2003. Habitat-associated morphological divergence in two Neotropical fish species. Biological Journal of the Linnean Society, 80(4): 689-698.

Muir, A.M., Bronte, C.R., Zimmerman, M.S., Quinlan, H.R., Glase, J.D. and Krueger, C.C., 2014. Ecomorphological diversity of lake trout at Isle Royale, Lake Superior. Transactions of the American Fisheries Society, 143(4): 972-987.

Nguyen, T.N.T., and Duong, T.Y., 2016. Morphological and genetic differences between cultured and wild populations of Channa striata in Viet Nam and its phylogenetic relationship with other Channa species. Songklanakarin Journal of Science and Technology, 38(4): 427-434.

Nguyen Phuong Thao and Duong Thuy Yen, 2017. Morphological diversity of kissing gourami (Helostoma temminkii Cuvier, 1829) in the Mekong Delta. Can Tho University Journal of Science 52, 78-85 (in Vietnamese).

Rainboth, W.J., 1996. Fishes of the Cambodian Mekong. FAO species identification field guide for fishery purposes (Vol. 53).

Šegvić-Bubić, T., Talijančić, I., Grubišić, L., IzquierdoGomez, D., and Katavić, I., 2014. Morphological and molecular differentiation of wild and farmed gilthead sea bream Sparus aurata: implications for management. Aquaculture Environment Interactions, 6(1): 43-54. 
Shine, R., 1989. Ecological causes for the evolution of sexual dimorphism: a review of the evidence. The Quarterly Review of Biology, 64(4): 419-461.

Sinh, L.X., Navy, H., and Pomeroy, R.S., 2014. Value chain of snakehead fish in the Lower Mekong Basin of Cambodia and Vietnam. Aquaculture Economics and Management, 18(1): 76-96.

Song, L.M., Munian, K., Abd Rashid, Z., and Bhassu, S., 2013. Characterisation of Asian snakehead Murrel Channa striata (Channidae) in Malaysia: An insight into molecular data and morphological approach. The Scientific World Journal, 2013: 1-16.

Tran, D.D., Shibukawa, K., Nguyen, T.P., et al., 2013. Fishes of the Mekong Delta, Viet Nam. Cantho University Publishing House.

Turan, C., Yalçin, Ş., Turan, F., et al., 2005. Morphometric comparisons of African catfish, Clarias gariepinus, populations in Turkey. Folia Zoologica, 54(1-2): 165-172.
Valentin, A.E., Penin, X., Chanut, J.P., Sévigny, J.M., and Rohlf, F.J., 2008. Arching effect on fish body shape in geometric morphometric studies. Journal of Fish Biology, 73(3): 623-638.

Ward-Campbell, B.M.S., and Beamish, F.W.H., 2005. Ontogenetic changes in morphology and diet in the snakehead, Channa limbata, a predatory fish in western Thailand. Environmental Biology of Fishes, 72(3): 251-257.

Wimberger, P.H., 1992. Plasticity of fish body shape. The effects of diet, development, family and age in two species of Geophagus (Pisces: Cichlidae). Biological Journal of the Linnean Society, 45(3): 197-218.

Wringe, B.F., Fleming, I.A., and Purchase, C.F., 2015. Rapid morphological divergence of cultured cod of the northwest Atlantic from their source population. Aquaculture Environment Interactions, 7(2): 167-177. 